\title{
Active Surveillance for T1bNOM0 Papillary Thyroid Carcinoma
}

\author{
Toshihiko Sakai, ${ }^{1}$ Iwao Sugitani, ${ }^{1,2}$ Aya Ebina, ${ }^{1}$ Osamu Fukuoka, ${ }^{3}$ Kazuhisa Toda, \\ Hiroki Mitani, ${ }^{1}$ and Keiko Yamada ${ }^{4}$
}

Background: Prospective trials of active surveillance for asymptomatic papillary microcarcinoma (T1aN0M0) since the 1990s have shown progression rates of only 5-10\%. Late rescue surgery after progression had no deleterious effects on mortality and morbidity. The 2015 American Thyroid Association guidelines approved active surveillance for very low-risk papillary thyroid carcinoma (PTC) as an alternative method to immediate surgery. However, there is no study that evaluates long-term active surveillance for T1b tumors.

Methods: A prospective trial of active surveillance with 360 very low-risk PTC (T1aN0M0) patients has been conducted since 1995. Of the 392 T1bNOM0 patients, 61 selected active surveillance over surgery and eventually participated in this trial, while the remaining 331 patients underwent surgery. To find an appropriate management strategy for patients with T1bN0M0 PTC, the outcomes of active surveillance for T1bN0M0 to T1aN0M0 PTC were investigated and compared, and the outcomes of surgery for T1bN0M0 PTC were studied. Results: After a mean of 7.4 years of active surveillance, $29(8 \%)$ T1aNOM0 tumors and four (7\%) T1bN0M0 tumors had increased in size $(p=0.69)$. Development of lymph node metastasis was seen in three $(0.8 \%)$ patients and two $(3 \%)$ patients, respectively $(p=0.10)$. No significant difference in progression rate was seen between groups. Among T1bN0M0 tumors, weak calcification and rich vascularity were risk factors for tumorsize increase, and younger age was a predictor for the development of lymph node metastasis. Mean initial tumor size was significantly greater in T1bN0M0 patients who underwent immediate surgery $(14.5 \pm 2.8 \mathrm{~mm})$ than it was in patients who chose observation $(11.7 \pm 1.1 \mathrm{~mm} ; p<0.0001)$. No postoperative recurrence was seen in patients with tumor $<15 \mathrm{~mm}$ in diameter.

Conclusions: Active surveillance is an option for selected patients with T1bN0M0 PTC.

Keywords: active surveillance, observation, thyroid cancer, microcarcinoma, overtreatment

\section{Introduction}

I $\mathrm{N}$ THE LAST FEW DECADES, rapid increases in the incidence of thyroid carcinoma have been reported from many developed countries, including the United States and South Korea (1-3). These increases are mainly due to increases in the incidence of small papillary thyroid carcinomas (PTC). This is generally attributed to the widespread use of more sensitive diagnostic procedures, including high-resolution ultrasonography (US). Autopsy series have indicated a frequency of latent papillary microcarcinoma (PMC) of at least $4-11 \%$ in the general population (4). Aggressive evaluation of small thyroid nodules with US and US-guided fine-needle aspiration (FNA) can find these very large subclinical reservoirs. Mortality rates from thyroid cancer have remained largely stable, despite the marked increases in incidence rates. Currently, preventing overdiagnosis and overtreatment of these very low-risk PTCs is becoming one of the most important issues in the management of thyroid carcinoma.

At two Japanese institutions, Kuma Hospital and Cancer Institute Hospital, prospective clinical trials have been conducted to verify the safety of active surveillance for patients with asymptomatic PMC (T1aN0M0) since the 1990s. As reported in 2010, active surveillance was carried out for 300 lesions in 230 patients at the Cancer Institute Hospital between 1995 and 2008 (5). Among those lesions, 7\% had increased in size, $90 \%$ were unchanged, and $3 \%$ had decreased. Three $(1 \%)$ patients developed apparent lymph node metastasis (LNM), but no patients showed extrathyroidal invasion or distant metastasis. None of the patients treated with surgery after progression developed tumor recurrence. The report from Kuma Hospital in 2014 showed that $8 \%$ and $3.8 \%$ exhibited

\footnotetext{
${ }^{1}$ Division of Head and Neck and ${ }^{4}$ Department of Ultrasonography, Cancer Institute Hospital, Tokyo, Japan.

${ }^{2}$ Department of Endocrine Surgery, Nippon Medical School, Tokyo, Japan.

${ }^{3}$ Department of Otolaryngology and Head and Neck Surgery, University of Tokyo, Tokyo, Japan.
} 
tumor size enlargement and novel node metastasis, respectively, among 1235 patients at the 10-year observation (6). Delayed rescue surgery after detection of signs of progression did not lead to significant recurrence or mortality. According to these favorable outcomes, the Japanese Clinical Guidelines for treatment of thyroid tumor published in 2010 approved a policy of active surveillance for patients with asymptomatic PMC for the first time in the world (7). Subsequently, the American Thyroid Association (ATA) management guidelines for adult patients with thyroid nodules and differentiated thyroid cancer revised in 2015 also endorsed active surveillance as an alternative to immediate surgery for properly selected patients with very low-risk tumors (8).

The American Joint Committee on Cancer (AJCC) and Union for International Cancer Control (UICC) tumor-nodemetastasis (TNM) system for differentiated thyroid carcinoma (DTC) classifies T1a as a tumor $\leq 1 \mathrm{~cm}$ without extrathyroidal extension and $\mathrm{T} 1 \mathrm{~b}$ as a tumor $>1 \mathrm{~cm}$ but $\leq 2 \mathrm{~cm}$ in greatest dimension without extrathyroidal invasion $(9,10)$. Several studies have pointed out that patients with a T1 tumor without clinically apparent nodal metastasis or distant metastasis (T1N0M0) show excellent prognoses after surgery without postoperative radioactive iodine treatment $(11,12)$. Although active surveillance for patients with T1aN0M0 tumor has been accepted as appropriate management, little research has reported on the long-term validity of active surveillance for T1bN0M0 tumors. To establish an appropriate management strategy for patients with T1bN0M0 PTC, the present study investigated and compared outcomes of active surveillance for patients with T1bN0M0 to T1aN0M0 tumors. The outcomes of immediate surgery for patients with T1bN0M0 PTC were also studied.

\section{Methods}

A prospective trial of active surveillance for patients with low-risk PTC has been conducted since 1995 at the Cancer Institute Hospital, a tertiary cancer referral center in Tokyo, Japan. As of 2016, a total of 798 patients had been diagnosed with clinical T1N0M0 PTC by US-guided FNA cytology. All patients are evaluated for the presence of clinically apparent extrathyroidal invasion, lymphadenopathy (maximum diameter $\geq 1 \mathrm{~cm}$ ), and distant metastasis using neck US and lung computed tomography (CT). Patients with asymptomatic PMC (T1aN0M0) were considered as candidates for the clinical trial of active surveillance. Detailed information was provided regarding the option of nonsurgical observation in addition to immediate surgery, and the patients chose the treatment themselves (5). For patients with T1bN0M0 PTC, surgery was generally recommended, but if the patient requested active surveillance, the final decision was made by the physician, taking into consideration the patient's age, tumor size, and other risk factors.

Among 406 patients with T1aN0M0 PTC, 360 (89\%) chose active surveillance and $46(11 \%)$ underwent immediate surgery. On the other hand, $331 / 392(84 \%)$ patients with T1bN0M0 PTC underwent immediate surgery, and 61 (16\%) chose active surveillance.

Patients who participated in the active surveillance program were followed with palpation, US, and chest radiography every 6 or 12 months after diagnosis to check for tumor enlargement, development of LNM, or distant metastasis. Diagnostic B-mode gray-scale US $(5.0-13.0 \mathrm{MHz}$ linear transducer) was performed by a single experienced radiologist (K.Y.) who specializes in thyroid US to evaluate tumor status and cervical LNM. Calcification patterns and vascularity were also recorded using both gray-scale and color Doppler US (13). Increased or decreased tumor size was defined as a change in maximum tumor diameter $\geq 3 \mathrm{~mm}$ on US from the start of observation. At the same time, the tumor volumes were calculated using the ellipsoid equation: $\pi / 6 \times$ length $\times$ width $\times$ height and calculated relative to the baseline. A relevant change in volume was defined as $>50 \%$ increase from baseline (14). Either tumor enlargement or development of metastasis was defined as "progression." Surgery was recommended during follow-up if the patient met the following criteria: (i) change in patient preference; (ii) tumor at risk for extrathyroidal extension to the recurrent laryngeal nerve, trachea, and esophagus; or (iii) signs of progression were detected. These protocols were approved by the ethics committee of the Cancer Institute Hospital in 1994. Written informed consent for participation in this study was obtained after agreement based on the informed decision of the patient.

In the case of immediate or delayed rescue surgery, lobectomy was carried out as a principal procedure according to a risk-adapted management policy $(5,15,16)$. Total thyroidectomy was conducted only for patients with bilateral lesions or autoimmune thyroid disease. As for lymph node dissection, prophylactic central node dissection and selective therapeutic lateral neck dissection were performed (17). Patients who underwent surgery were followed by US and chest radiography or lung $\mathrm{CT}$ every year to check for recurrence.

\section{Statistical analysis}

Data are expressed as the mean \pm standard deviation. Comparison of clinical characteristics between groups was performed using the chi-square test for categorical variables and the $t$-test for continuous variables. Time-dependent variables were analyzed using the Kaplan-Meier method and were compared using the log-rank test. All analyses were performed using JMP for Windows v10.0.2 (SAS Institute, Cary, NC). $p$-Values of $<0.05$ were considered statistically significant.

\section{Results}

\section{Clinical characteristics}

The clinical characteristics and outcomes of patients with T1aN0M0 PTC and T1bN0M0 PTC are shown in Table 1. Comparing the active surveillance groups of $\mathrm{T} 1 \mathrm{a}$ and $\mathrm{T} 1 \mathrm{~b}$, the male-to-female ratio was significantly greater for $\mathrm{T} 1 \mathrm{~b}$ than for T1a $(p=0.02)$. No significant differences in age or follow-up period were seen between the same groups. Comparing the clinical characteristics of T1bN0M0 patients who had active surveillance and those who underwent immediate surgery, no significant differences in sex or age were evident between groups. Mean tumor size was significantly larger in the surgery group $(14.5 \mathrm{~mm})$ than in the active surveillance group $(11.7 \mathrm{~mm} ; p<0.0001)$.

\section{Outcomes of active surveillance}

The mean observation period was 7.4 years (range $0.5-25$ years) in T1N0M0 PTC, 7.3 years (range 0.5-25 years) in T1aN0M0 PTC, and 7.9 years (range 1-17 years) in T1bN0M0 PTC. There were no differences in the prevalence of 
Table 1. Clinical Characteristics and Outcomes of Patients with T1a and T1b PTC

\begin{tabular}{|c|c|c|c|c|}
\hline & & \multirow{2}{*}{$\frac{T 1 a}{\begin{array}{c}\text { Active surveillance } \\
(\mathrm{n}=360)\end{array}}$} & \multicolumn{2}{|c|}{$T 1 b$} \\
\hline & & & $\begin{array}{c}\text { Active surveillance } \\
\qquad(\mathrm{n}=61)\end{array}$ & $\begin{array}{l}\text { Surgery } \\
(\mathrm{n}=331)\end{array}$ \\
\hline Sex & Male (rate) & $41(11 \%)$ & $14(23 \%)^{*}$ & $52(16 \%)$ \\
\hline Age & $\begin{array}{l}M \pm S D \\
\text { (range) }\end{array}$ & $\begin{array}{c}53.9 \pm 12.0 \\
(23-84)\end{array}$ & $\begin{array}{c}54.4 \pm 10.7 \\
(32-78)\end{array}$ & $\begin{array}{c}51.9 \pm 12.6 \\
(17-82)\end{array}$ \\
\hline Tumor size (mm) & $\begin{array}{l}M \pm S D \\
\text { (range) }\end{array}$ & $\begin{array}{c}7.6 \pm 1.8 \\
(2-10)\end{array}$ & $\begin{array}{c}11.7 \pm 1.1^{* *} \\
(11-16)\end{array}$ & $\begin{array}{c}14.5 \pm 2.8^{* * *} \\
(11-20)\end{array}$ \\
\hline Comorbidity of malignant tumor & & $88(24 \%)$ & $13(21 \%)$ & $71(21 \%)$ \\
\hline Follow-up period (years) & $\begin{array}{l}M \pm S D \\
\text { (range) }\end{array}$ & $\begin{array}{l}7.3 \pm 4.3 \\
(0.5-25)\end{array}$ & $\begin{array}{c}7.9 \pm 4.0 \\
(1-17)\end{array}$ & \\
\hline Diameter increase of $\geq 3 \mathrm{~mm}$ & & $29(8 \%)$ & $4(7 \%)$ & \\
\hline Volume increase of $\geq 50 \%$ & & $74(21 \%)$ & $7(11 \%)$ & \\
\hline Development of clinical LNM & & $3(1 \%)$ & $2(3 \%)$ & \\
\hline
\end{tabular}

*T1a vs. T1b; $p=0.02$.

${ }^{* * *}$ T1a vs. T1b; $p<0.001$.

*** Active surveillance vs. surgery; $p<0.0001$.

PTC, papillary thyroid carcinoma; LNM, lymph node metastasis.

comorbidity of malignant tumors between T1a active surveillance cases, T1b active surveillance cases, and T1b surgery cases. After active surveillance, $29(8 \%)$ patients with T1aN0M0 PTC and four (7\%) patients with T1bN0M0 had shown an increase in maxima tumor diameter of $\geq 3 \mathrm{~mm}$ $(p=0.69)$. Seventy-four $(21 \%)$ patients with T1aN0M0 PTC and seven $(11 \%)$ patients with T1bNOM0 had shown an increase in tumor volume $\geq 50 \%(p=0.10)$. Development of LNM was seen in three (1\%) patients with T1aN0M0 and two (3\%) patients with T1bNOM0 $(p=0.10)$. None of the events showed a significant difference between T1a and T1b. The five-year progression rate was $5 \%$ for both $\mathrm{T} 1 \mathrm{a}$ and $\mathrm{T} 1 \mathrm{~b}$, and the 10 -year progression rate was $12 \%$ for both. No significant difference in time-dependent progression rate was evident between groups.

Predictors of tumor size enlargement and development of LNM from T1b PTC are shown in Table 2. Univariate analysis among T1bNOM0 tumors revealed that noncalcification pattern and rich vascularity in the tumor were associated with a higher rate of tumor enlargement, while lower age was a risk factor for LNM development.

\section{Outcomes of immediate surgery for T1b}

Among patients who received immediate surgery for $\mathrm{T} 1 \mathrm{~b}$ PTC, eight patients showed recurrence, at the remnant thyroid in two $(0.6 \%)$ cases, at lymph nodes in five $(1.3 \%)$ cases, and at distant sites in one $(0.3 \%)$ case. Recurrence did not occur in patients with a maximal tumor diameter $<15 \mathrm{~mm}$. The five-year disease-free survival (DFS) rate for PTC $\geq 15 \mathrm{~mm}$ was $99 \%$, and the 10 -year DFS was $95 \%$. The recurrence rate for PTC $\geq 15 \mathrm{~mm}$ was significantly higher than that for PTC $<15 \mathrm{~mm}(p=0.017)$.

\section{Outcomes of surgery after active surveillance for $T 1 b$}

Eleven patients underwent surgery after active surveillance. None of these patients showed recurrence during the follow-up period. The treatment strategy was switched to surgery for several reasons. The most common reason was a request from the patient (five cases), followed by tumor enlargement (four cases), and development of LNM and extrathyroidal infiltration (one case each).

No significant differences in surgical procedures, complications, or overall rate of recurrence were seen between the surgery after active surveillance group and the immediate surgery group.

\section{Discussion}

Recently, it has been realized that detecting and treating small, intrathyroidal PTC does not result in decreased

Table 2. Risk Factors for Tumor Size Enlargement and Development OF LNM IN T1B (UNIVARIATE ANALYSIS)

\begin{tabular}{|c|c|c|c|c|c|c|}
\hline \multirow[b]{2}{*}{ Risk factor } & \multicolumn{3}{|c|}{ Size change } & \multicolumn{3}{|c|}{ Development of $L N M$} \\
\hline & $\begin{array}{l}\text { No change } \\
(\mathrm{n}=57)\end{array}$ & $\begin{array}{c}\text { Enlargement } \\
(\mathrm{n}=4)\end{array}$ & $\mathrm{p}$ & $\begin{array}{l}\text { Development of } \\
\text { LNM- }(\mathrm{n}=59)\end{array}$ & $\begin{array}{l}\text { Development of } \\
\text { LNM+ }(\mathrm{n}=2)\end{array}$ & $\mathrm{p}$ \\
\hline $\begin{array}{l}\text { Sex } \\
\text { (Male) }\end{array}$ & $14(25 \%)$ & 0 & 0.26 & $14(24 \%)$ & 0 & 0.43 \\
\hline $\begin{array}{l}\text { Age } \\
\quad(\text { Mean } \pm \text { SD })\end{array}$ & $54.7 \pm 10.8$ & $49.5 \pm 6.2$ & 0.35 & $55.0 \pm 10.3$ & $37.5 \pm 7.8$ & 0.02 \\
\hline $\begin{array}{l}\text { Tumor size } \\
\quad(\text { Mean } \pm \text { SD })\end{array}$ & $11.7 \pm 1.1$ & $11.5 \pm 0.6$ & 0.69 & $11.7 \pm 1.1$ & $11.0 \pm 0$ & 0.37 \\
\hline Non-calcification pattern & $3(5 \%)$ & $3(75 \%)$ & $<0.0001$ & $6(10 \%)$ & 0 & 0.63 \\
\hline Rich vascularity & $10(18 \%)$ & $3(75 \%)$ & 0.01 & $12(20 \%)$ & $1(50 \%)$ & 0.31 \\
\hline
\end{tabular}


mortality from thyroid cancer. Overdiagnosis and overtreatment of very low-risk PTC has thus been an emerging issue not only for patient quality of life, but also for public health management. To prevent overdiagnosis of subclinical PTC, the U.S. Preventive Services Task Force recommended against screening for thyroid cancer in asymptomatic adults using either neck palpation or US in 2017 (18). The ATA management guidelines for adult patients with thyroid nodules and differentiated thyroid cancer do not recommend FNA cytology for sub-centimeter thyroid nodules, even if the nodule shows a suspicious pattern on ultrasonography (8). The Japan Society of Ultrasonics in Medicine and the Japan Association of Breast and Thyroid Sonology recommend observation for solid thyroid nodules with a diameter of $\leq 5 \mathrm{~mm}$. For solid nodules measuring $5-10 \mathrm{~mm}$, FNA is advocated only when features highly suggestive of malignancy are present on US (19).

As a modality to reduce overtreatment for patients who have been already diagnosed with asymptomatic PMC, the policy of active surveillance has been accepted as a safe procedure in both Japanese and U.S. guidelines $(7,8)$. Based on the accumulated data, this approach could be more beneficial and costeffective for patients and society than immediate surgery $(5,6,20,21)$. Clinical trials of active surveillance for patients with T1aN0M0 PTC have been conducted in Japan since the 1990s. Subsequently, similar studies have also been launched in the United States and Korea $(14,22)$.

Usually, the indication for active surveillance is limited to T1aN0M0 PTC, excluding T1bN0M0. However, Anderson et al. (12) reported similar overall and disease-specific survival rates after surgery between patients with $\mathrm{T} 1 \mathrm{a}$ and $\mathrm{T} 1 \mathrm{~b}$ tumors who underwent surgery using a large pool of data from the National Cancer Date Base $(98,111$ cases of T1a and 51,801 cases of T1b) and the Surveillance, Epidemiology, and End Results program (11,208 cases of T1a and 7,173 cases of T1b). Few published studies to date have evaluated long-term active surveillance for T1b tumors. A trial from the Memorial Sloan Kettering Cancer Center included 59 patients with intrathyroidal $\mathrm{T} 1 \mathrm{~b}(\leq 1.5 \mathrm{~cm})$ tumors (14). Among those, two $(3.4 \%)$ patients showed a tumor diameter increase of $\geq 3 \mathrm{~mm}$. This was not significantly different from patients with T1a tumors $(9 / 232 ; 3.9 \%)$, but the median follow-up period was only 25 months (range 6-166 months).

The present study was a prospective trial of active surveillance for 61 patients with T1bN0M0 PTC. The mean observation period was 7.9 years (range 1-17 years). Although a greater number of patients and longer follow-up period are needed, the progression rate did not differ significantly from that of T1aN0M0 PTC, and delayed rescue surgery was not associated with any deleterious outcomes. This represents the first report to suggest the safety of long-term active surveillance for patients with T1bN0M0 PTC. This study also examined the risk of progression under active surveillance for T1b tumors. Risk factors for tumor size enlargement were a non-calcification pattern and rich vascularity, and the only risk factor identified for LNM was younger age. These results were almost the same as findings from previous studies for $\mathrm{T} 1 \mathrm{a}$ tumors $(5,6,13,23)$. It has previously been shown that the grade of tumor calcification correlated with age at diagnosis, and that the majority of tumors exhibited an upgraded calcification pattern during observation. Moreover, the incidence of tumor enlargement tended to be inversely related to the grade of calcification (13). Investigators from Kuma Hospital also reported age as an independent predictor of progression by multivariate analysis (6). Miyauchi et al. (23) recently estimated lifetime disease progression probabilities as $60 \%$ for the 20 s, $37 \%$ for 30 s, $27 \%$ for 40 s, $15 \%$ for 50 s, and $10 \%$ for 60 s according to the age at the start of active surveillance for T1aN0M0 PTC. Even for T1bN0M0 PTC, older patients with a strong calcification pattern would be good candidates for active surveillance rather than immediate surgery.

Expanding the indications for active surveillance to T1b tumor might lead to reductions in surgery and avoid the risk of surgical complications. Griffin et al. (24) examined the proportion of PTC that would meet the criteria for active surveillance as proposed by the Memorial Sloan Kettering Cancer Center with Kuma Hospital (25). Among 243 patients with PTC who underwent surgery, 27 had nodules $\leq 1 \mathrm{~cm}$, and 15 of these would have been appropriate for active surveillance according to the criteria. Fifty patients had nodules $1.1-1.5 \mathrm{~cm}$ in diameter, of whom 41 would have been ideal or appropriate for active surveillance. Of these 56 patients who met the criteria for active surveillance, 52 had undergone total thyroidectomy, and 45 had elective central nodal dissection. Eventually, three patients developed permanent complications from surgery, including vocal cord paralysis, hypoparathyroidism, and a chipped tooth from intubation. No patients died or developed recurrent disease. Griffin et al. concluded that increasing the size threshold for active surveillance of PTC to $1.5 \mathrm{~cm}$ led to a quarter of patients being eligible compared to only $6 \%$ with the $1 \mathrm{~cm}$ threshold. Without an active surveillance program, the majority of patients with low-risk cancer undergo thyroidectomy, which carries a small risk of permanent surgical complications.

As mentioned above, the thyroid cancer disease management team at Memorial Sloan Kettering Cancer Center collaborated with Kuma Hospital to develop a risk-stratified clinical decision-making framework for selecting candidates for active surveillance of PMC (25). The risk-stratification framework comprised three domains: tumor/neck US characteristics (size of the primary tumor, location of the tumor within the thyroid gland), patient characteristics (age, comorbidities, willingness to accept observation), and medical team characteristics (availability and experience of the multidisciplinary team). Based on these criteria, patients with probable or proven PTC can then be classified as ideal, appropriate, or inappropriate candidates for active surveillance. In this study, active surveillance was applied to the patients with the smaller T1b tumors. The mean tumor size was $11.7 \mathrm{~mm}$ (range 11-16 mm), and two patients with $\geq 15 \mathrm{~mm}$ tumors underwent active surveillance. Our study also shows favorable outcomes of immediate surgery for patients with T1bN0M0 PTC. Particularly, patients with tumor size $<15 \mathrm{~mm}$ never showed recurrences. They may represent very low-risk cancer, and it may be possible to conclude that adoption of active surveillance for PTCs $<15 \mathrm{~mm}$ in diameter is safe and reasonable. Careful risk stratification using the proposed decision-making framework is clearly important to improve patient outcomes and safety with the active surveillance management option.

\section{Author Disclosure Statement}

No competing financial interests exist.

\section{References}

1. Davies L, Welch HG 2006 Increase incidence of thyroid cancer in the United States, 1973-2002. JAMA 295:2164-2167. 
2. Davies L, Welch HG 2014 Current thyroid cancer trends in the United States. JAMA Otolaryngol Head Neck Surg 140: 317-322.

3. Ahn HS, Kim HJ, Welch HG 2014 The Republic of Korea's thyroid-cancer "epidemic"-screening and overdiagnosis. N Engl J Med 371:1765-1767.

4. Furuya-Kanamori L Bell KJ, Clark J, Glasziou P, Doi SA 2016 Prevalence of differentiated thyroid cancer in autopsy studies over six decades: a meta-analysis. J Clin Oncol 34: 3672-3679.

5. Sugitani I, Toda K, Yamada K, Yamamoto N, Ikenaga M, Fujimoto Y 2010 Three distinctly different kinds of papillary thyroid microcarcinoma should be recognized: our treatment strategies and outcomes. World J Surg 34:1222-1231.

6. Ito Y, Miyauchi A, Kihara M, Higashiyama T, Kobayashi K, Miya A 2014 Patient age is significantly related to the progression of papillary microcarcinoma of the thyroid under observation. Thyroid 24:27-34.

7. Imai T, Kitano H, Sugitani I, Wada N 2013 CQ20. When can papillary microcarcinoma (papillary carcinoma measuring $1 \mathrm{~cm}$ or less) be observed without immediate surgery? In: Takami H, Ito $\mathrm{Y}$, Noguchi H, et al. (eds) Treatment of Thyroid Tumor: Japanese Clinical Guidelines. Tokyo, Springer Japan, pp 119-122.

8. Haugen BR, Alexander EK, Bible KC, Doherty GM, Mandel SJ, Nikiforov YE, Pacini F, Randolph GW, Sawka AM, Schlumberger M, Schuff KG, Sherman SI, Sosa JA, Steward DL, Tuttle R, Michael L, Wartofsky L 20162015 American Thyroid Association management guidelines for adult patients with thyroid nodules and differentiated thyroid cancer: the American Thyroid Association Guidelines Task Force on Thyroid Nodules and Differentiated Thyroid Cancer. Thyroid 26:1-133.

9. Brierley JD, Gospodarowicz MK, Wittekind Ch (eds) 2017 TNM Classification of Malignant Tumours. Eighth edition. Wiley-Blackwell, Chichester, United Kingdom.

10. Amin MB, Edge S, Greene F, Byrd DR, Brookland RK, Washington MK, Gershenwald JE, Compton CC, Hess KR, Sullivan DC, Jessup JM, Brierley JD, Gaspar LE, Schilsky RL, Balch CM, Winchester DP, Asare EA, Madera M, Gress DM, Meyer LR (eds) 2016 AJCC Cancer Staging Manual. Eighth edition. Springer, New York, NY.

11. Ito Y, Masuoka H, Fukushima M, Inoue H, Kihara M, Tomoda C, Higashiyama T, Takamura Y, Kobayashi K, Miya A, Miyauchi A 2010 Excellent prognosis of patients with solitary T1N0M0 papillary thyroid carcinoma who underwent thyroidectomy and elective lymph node dissection without radioiodine therapy. World J Surg 34:1285-1290.

12. Anderson KL Jr, Youngwirth LM, Scheri RP, Stang MT, Roman SA, Sosa JA 2016 T1a versus T1b differentiated thyroid cancers: do we need to make the distinction? Thyroid 26:1046-1052.

13. Fukuoka O, Sugitani I, Ebina A, Toda K, Kawabata K, Yamada K 2016 Natural history of asymptomatic papillary thyroid microcarcinoma: time-dependent changes in calcification and vascularity during active surveillance. World $\mathbf{J}$ Surg 40:529-537.

14. Tuttle RM, Fagin JA, Minkowitz G, Wong RJ, Roman B, Patel S, Untch B, Ganly I, Shaha AR, Shah JP, Pace M, Li D, Bach A, Lin O, Whiting A, Ghossein R, Landa I, Sabra M, Boucai L, Fish S, Morris LGT 2017 Natural history and tumor volume kinetics of papillary thyroid cancers during active surveillance. JAMA Otolaryngol Head Neck Surg 143:1015-1020.
15. Sugitani I, Kasai N, Yanagisawa A 2004 A novel classification system for patients with PTC: addition of the new variables of large $(3 \mathrm{~cm}$ or greater) nodal metastases and reclassification during the follow-up period. Surgery 125:139-148.

16. Ebina A, Sugitani I, Fujimoto Y, Yamada K 2014 Riskadapted management of papillary thyroid carcinoma according to our own risk-group classification system: is thyroid lobectomy the treatment of choice for low-risk patients? Surgery 156:1579-1589.

17. Sugitani I, Fujimoto Y, Yamada K, Yamamoto N 2008 Prospective outcomes of selective lymph node dissection for papillary thyroid carcinoma based on preoperative ultrasonography. World J Surg 32:2494-2502.

18. US Preventive Services Task Force, Bibbins-Domingo K, Grossman DC, Curry SJ, Barry MJ, Davidson KW, Doubeni CA, Epling JW Jr, Kemper AR, Krist AH, Kurth AE, Landefeld CS, Mangione CM, Phipps MG, Silverstein M, Simon MA, Siu AL, Tseng CW 2017 Screening for thyroid cancer: US Preventive Services Task Force recommendation statement. JAMA 317:1882-1887.

19. Terminology and Diagnostic Criteria Committee, Japan Society of Ultrasonic in Medicine 2012 Ultrasound diagnostic criteria for thyroid nodule. J Med Ultrason (2001) 39:49-50.

20. Oda H, Miyauchi A, Ito Y, Yoshioka K, Nakayama A, Sasai H, Masuoka H, Yabuta T, Fukushima M, Higashiyama T, Kihara M, Kobayashi K, Miya A 2016 Incidences of unfavorable events in the management of low-risk papillary microcarcinoma of the thyroid by active surveillance versus immediate surgery. Thyroid 26:150-155.

21. Oda H, Miyauchi A, Ito Y, Sasai H, Masuoka H, Yabuta T, Fukushima M, Higashiyama T, Kihara M, Kobayashi K, Miya A 2017 Comparison of the costs of active surveillance and immediate surgery in the management of low-risk papillary microcarcinoma of the thyroid. Endocr J 64:59-64.

22. Kwon H, Oh HS, Kim M, Park S, Jeon MJ, Kim WG, Kim WB, Shong YK, Song DE, Baek JH, Chung KW, Kim TY 2017 Active surveillance for patients with papillary thyroid microcarcinoma: a single center's experience in Korea. J Clin Endocrinol Metab 102:1917-1925.

23. Miyauchi A, Kudo T, Ito Y, Oda H, Sasai H, Higashiyama T, Fukushima M, Masuoka H, Kihara M, Miya A 2018 Estimation of the lifetime probability of disease progression of papillary microcarcinoma of the thyroid during active surveillance. Surgery 163:48-52.

24. Griffin A, Brito JP, Bahl M, Hoang JK 2017 Applying criteria of active surveillance to low-risk papillary thyroid cancer over a decade: how many surgeries and complications can be avoided? Thyroid 23:518-523.

25. Brito JP, Ito Y, Miyauchi A, Tuttle RM 2016 A clinical framework to facilitate risk stratification when considering an active surveillance alternative to immediate biopsy and surgery in papillary microcarcinoma. Thyroid 26:144-149.

Address correspondence to: Toshihiko Sakai, MD

Division of Head and Neck Cancer Institute Hospital 3-8-31 Ariake Koto-ku

Tokyo 135-8550 Japan

E-mail: tsakai8312@gmail.com 